\title{
Ontogenetic reaction norm for binary traits: the timing of phallus development in the snail Bulinus truncatus
}

\author{
M-F Ostrowski, P Jarne, O Berticat and P David \\ CEFE-CNRS, 1919 route de Mende, 34293 Montpellier cedex 5, France
}

\begin{abstract}
The ontogenetic trajectory of plastic binary traits may provide valuable insights into their evolutionary rate of change. In this paper, the timing of the plastic response of a temperature-dependent sexual polymorphism, aphally, is investigated in the freshwater snail Bulinus truncatus. Aphally is defined as the loss of the male copulatory organ in otherwise hermaphroditic animals. Individuals from two inbred lines were switched at various times during their early development between 25 and $30^{\circ} \mathrm{C}$, and their phally status ascertained, in order to evaluate the parameters characterising the ontogenetic reaction norm of aphally to temperature. A series of nested models including parameters for the onset,
\end{abstract}

offset, and the intensity of the response to temperature were fitted to the data, allowing for a wide range of reaction norms. One genotype did not show any variation in aphally ratio with switching temperature, while a switch-point model (onset and offset corresponding to the same developmental point in time) best fitted the second genotype. The results suggest that the plasticity of aphally is expressed before eggs hatch. Their consequences on the evolution of aphally are discussed. More generally, the methodology proposed here can be used to analyse variation in ontogenetic parameters of discrete traits.

Heredity (2002) 88, 342-348. DOI: 10.1038/sj/hdy/6800049

Keywords: binary traits; ontogenetic parameters; reaction norm; sexual polymorphism; freshwater snail

\section{Introduction}

Sexes and sexual polymorphisms are examples of discrete traits extensively studied for their complex genetic determinism and usually analysed under the threshold model (Roff, 1997; Lynch and Walsh, 1998). Increasing attention has been given to the plasticity of such traits in relation to various environmental variables (eg, temperature, light, host quality: Waller, 1980; Charnov, 1982; Janzen and Paukstis, 1991; Paoletti and Holsinger, 1999; Roff and Bradford, 1999). More recently, the importance of genotype-by-environment interactions has been attested by several studies (Rhen and Lang, 1998; Ostrowski et al, 2000). Surprisingly though, the ontogenetic aspects of this plasticity have been far less considered. However, characterising the developmental timing of plasticity is relevant to the study of the evolution of discrete plastic traits. It defines a time window during which the organism is sensitive to the environment and 'picks' the form it will assume at the adult stage. Because the expected fitness may depend on this decision, selection is likely to optimise the amount of environmental information collected by the organism by shaping this window. Beyond that, the question of whether individuals passively undergo their environmental conditions during this window or are able to choose them to some extent is also of interest, because it modulates the effective amount of genetic variation on

Correspondence: M-F Ostrowski, CEFE-CNRS, 1919 route de Mende, 34293 Montpellier cedex 5, France.

E-mail: marie-france.ostrowski@cefe.cnrs-mop.fr

Received 20 July 2001; accepted 17 December 2001 which selection can act (Roff and Shannon, 1993). Habitat selection during development can indeed affect the apparent genetic variation of plastic discrete traits in different directions. First, assuming no correlation between genotype and environment, habitat selection will tend to reduce the variance due to environmental differences, improving the response to selection relatively to a situation where organisms develop in a wider range of environments (Bull et al, 1982). A further enhanced response would be obtained in presence of a positive correlation, that is if individuals were choosing environments that favour the expression of their genetic propensity. Conversely, a negative correlation would reduce the response. The latter case has been described for macroptery in the sand cricket Gryllus firmus. In this species, the timing of plasticity allows a habitat selection that could impede the evolution of macroptery in nature (Roff and Shannon, 1993).

Aphally is a sexual polymorphism defined by the cooccurrence of regular hermaphrodites, referred to as euphallic individuals, together with aphallic individuals which are deprived of a male copulatory organ. Both morphs can self-fertilise and outcross, though aphallics outcross only as females. Most studies on this trait have been conducted in the freshwater snail Bulinus truncatus. Aphally has a complex genetic basis together with a strong environmental determination (Doums et al, 1996; Ostrowski et al, 2000). An increase in developmental temperature yields a higher frequency of aphallic individuals (aphally ratio or AR), both in the laboratory (Schrag and Read, 1992; Doums et al, 1996) and in natural populations (Schrag et al, 1994). As macroptery, aphally could be affected by habitat selection of mobile individuals during 
the time window of its plasticity. Assessing the opportunity of such a habitat selection requires the evaluation of this plastic period. The aim of this paper is therefore to characterise the ontogenetic reaction norm of aphally in B. truncatus. Individuals from two inbred lines were transferred at various ages from a lower to a higher developmental temperature. The temporal change in expression of the phally status has been analysed using an original procedure that allows for a genotype-specific description of the ontogenetic reaction norm of plasticity to temperature.

\section{Materials and methods}

\section{Biological material and rearing conditions}

Bulinus truncatus is a highly selfing snail species (Larambergue, 1939; Viard et al, 1997). Isolated individuals start to lay eggs, when they are approximately $5 \mathrm{~mm}$ long under laboratory conditions (eg 25 days of age at $25^{\circ} \mathrm{C}$; Doums et al, 1998a). Eggs come in capsules containing up to 20 egg cells (Larambergue, 1939). Oviposition of egg capsules preceeds hatching of juveniles by about 5 to 10 days depending on the environmental conditions (Doums et al, 1998a). Aphallic individuals have been detected in almost all populations of B. truncatus so far studied, at frequencies generally higher than $50 \%$ (Doums et al, 1998b). The phally status seems to be determined (for life) around the egg and juvenile stages (Schrag and Read, 1992) and it can easily be checked in snails larger than three $\mathrm{mm}$ (Jarne et al, 1992). More information on the breeding biology and phally polymorphism in B. truncatus is given in Doums et al (1998a).

The experiment was conducted using two inbred lines. Each of these lines originated from a single founder individual obtained through at least 10 generations of controlled selfing from a single $G_{0}$ individual taken in a natural population from Niger (Kobouri and Namaga for line 1 and 2 respectively; see Doums et al (1996). The individuals used were therefore considered as wholly homozygous and genetically homogeneous within each line. Over the whole experiment, snails were maintained under a 12/12 photoperiod in 75-ml plastic boxes filled with water originating from the Lez spring (near Montpellier). Details on rearing temperatures are given below. Snails were fed ad libitum with boiled lettuce. Water and food were changed twice a week.

\section{General method}

The main quantitative parameters characterising the development of a continuous trait are typically the onset, offset and rate of its growth (Gould, 1977). An associated ontogenetic reaction norm has been defined by adding a temporal axis to the classical reaction norm (Pigliucci and Schlichting, 1995, Figure 1a). For plastic binary traits, ontogenetic parameters are better defined as the onset, offset and the temporal rate of change in the probability that an individual of a given genotype will end up in a given final state $s_{1}$. This cannot be estimated at the individual level but only as the frequency of the $s_{1}$ phenotype among a set of genetically similar individuals reared in the same conditions. Empirically, the ontogenetic reaction norm of a plastic binary trait is therefore constituted of a set of estimations with binomial errors. However, as the probability to end up in a given state during develop-
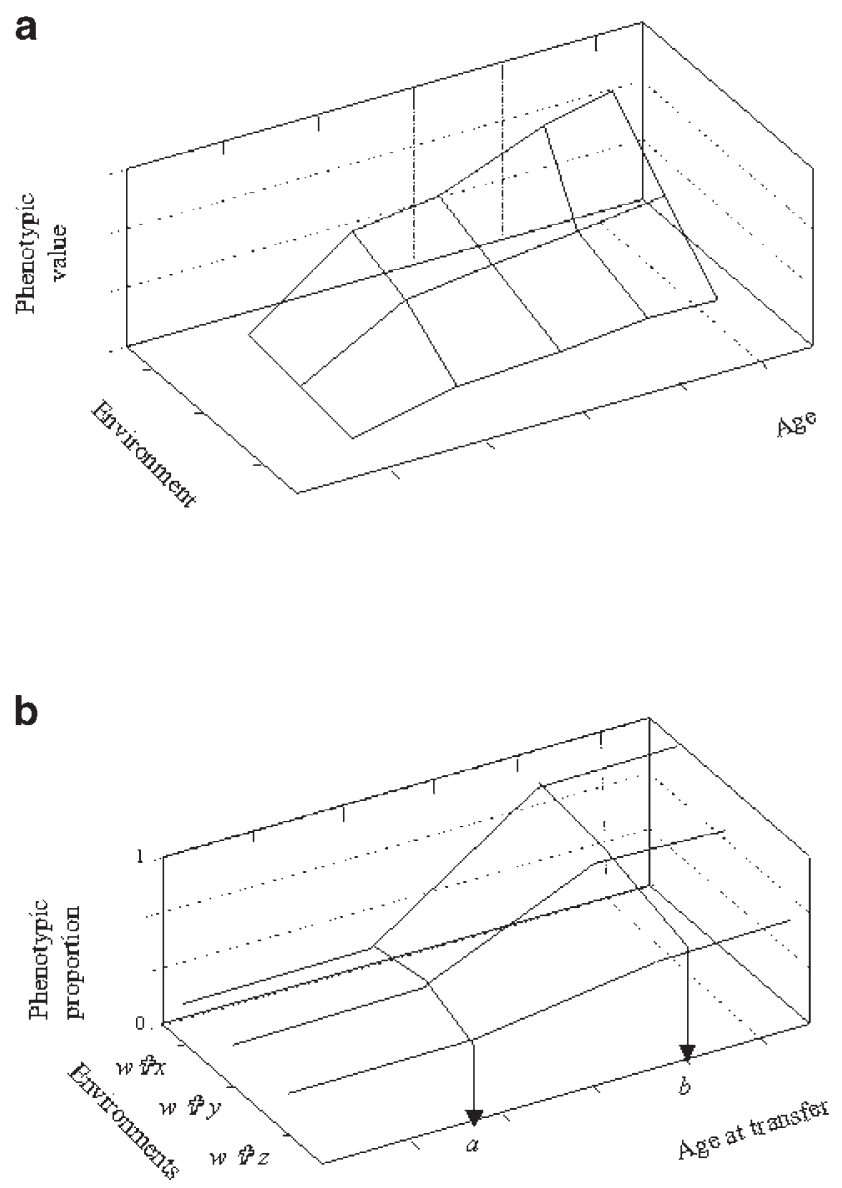

Figure 1 Ontogenetic reaction norms for continuous (A) and binary (B) characters. (a) The (Phenotype, Ontogeny, Environment) space defining the ontogenetic reaction norm of a continuous character for a hypothetical genotype in three environments over its lifespan (after Pigliucci and Schlichting, 1995). (b) The ontogenetic reaction norm of a plastic binary trait for a hypothetical genotype in three ordered pairs of environments over a time interval that includes the onset $(a)$ and the offset $(b)$ of the effect of the environmental variable. All individuals are born in the same initial reference environment $w$. Age at transfer refers to the age at which developing individuals are transferred from $w$ to one of the final environments $(x, y, z)$. Initial vs final environments are not exchangeable; the represented reaction norms are unilateral. The frequency of the $s_{1}$ phenotype is evaluated at the adult stage (age $>b)$.

ment is usually unknown until development is completed, the onset, offset and the temporal rate of change in this probability cannot be estimated without performing a switch experiment (Figure 1b). In such experiments, individuals are initially raised in, say, environment $A$, then transferred into environment $B$ at various times. Because of the possibility of asymmetric responses, the ontogenetic reaction norm estimated using such a protocol is a priori valid for the ordered pair A,B (Figure 1b).

\section{Experimental design}

Individuals were transferred from 25 to $30^{\circ} \mathrm{C}$ at various ages, that is from age -5 days to +25 days (Table 1 ). Age zero is the time when an individual is laid as eggs. Negative age classes correspond to individuals whose mother has been transferred to $30^{\circ} \mathrm{C}$ before the egg was collected. 
Table 1 Description of the 12 treatments in which either $G_{n+1}$ individuals (treatments 9 to 12 ), or $G_{n+2}$ individuals (treatments 1 to 8 ) were transferred from 25 to $30^{\circ} \mathrm{C}$

\begin{tabular}{lcccc}
\hline Treatment & $T_{1}$ & $T_{2}$ & $\begin{array}{c}\text { Median } \\
\text { time }\end{array}$ & $\begin{array}{c}\text { Time } \\
\text { range }\end{array}$ \\
\hline 1 & 25 & $25-30$ & 25 & 20 to 30 \\
2 & 25 & $25-30$ & 16.5 & 13 to 20 \\
3 & 25 & $25-30$ & 9.5 & 6 to 12 \\
4 & 25 & $25-30$ & 5 & 4 to 6 \\
5 & 25 & $25-30$ & 3 & 2 to 4 \\
6 & 25 & $25-30$ & 1.5 & 1 to 2 \\
7 & 25 & $25-30$ & 0.75 & 0.5 to 1 \\
8 & 25 & $25-30$ & 0.25 & 0 to 0.5 \\
9 & $25-30$ & 30 & -0.75 & -0.5 to -1 \\
10 & $25-30$ & 30 & -1.5 & -1 to -2 \\
11 & $25-30$ & 30 & -3 & -4 to -2 \\
12 & $25-30$ & 30 & -5 & -4 to -6 \\
\hline
\end{tabular}

$T_{1}$ refers to the temperature(s) successively experienced by $G_{n+1}$ (parent) individuals, and $T_{2}$ to that (those) successively experienced by $G_{n+2}$ (offspring) individuals. Median time and time range (in days) are the median time and its range spent by $\mathrm{G}_{n+2}$ individuals at $25^{\circ} \mathrm{C}$ (positive values), or by $\mathrm{G}_{\mathrm{n}+1}$ individuals at $25^{\circ} \mathrm{C}$ before transfer (negative values). Time range is also the time over which the capsules were collected for each treatment.

Positive age classes correspond to individuals transferred to $30^{\circ} \mathrm{C}$ as eggs or juveniles. Negative age classes were included to allow for maternally-mediated influence of temperature on immature oocytes or eggs.

Randomly chosen snails of the 10th laboratory generation $\left(G_{n}\right)$ from each of the two lines were isolated to produce parental snails $\left(G_{n+1}\right)$ of identical ages. Ten and $12 G_{n+1}$ snails for genotype 1 and 2 respectively were maintained isolated at $25^{\circ} \mathrm{C}$ and produced offspring $\left(G_{n+2}\right)$. The snails transferred from 25 to $30^{\circ} \mathrm{C}$ were either $\mathrm{G}_{n+1}$ individuals (negative age classes), or $\mathrm{G}_{n+2}$ individuals (positive age classes). Collection of egg capsules from $G_{n+1}$ snails was done over a period of about 40 days (22 April to 4 June 1999). The 12 treatments of the experiment are detailed in Table 1: $G_{n+2}$ snails were transferred from 25 to 0.25 days after having been laid as eggs (treatments 1 to 8 ) and $G_{n+1}$ snails were transferred from 0.75 to 5 days before their eggs were collected (treatments 9 to 12). As it is technically impracticable to determine the precise time when each egg was laid, age zero was set at the midpoint of the interval during which females of each treatment were allowed to lay eggs (see Table 1). Note that time intervals are much larger for treatments 1 to 4 and 12, because previous results suggested that the critical time for phallus development is around oviposition (Schrag and Read, 1992). Although we tried to compensate for potential imbalance in number of individuals across treatments by increasing the number of $G_{n+1}$ females used for short intervals, a consequence is that the number of $G_{n+2}$ individuals varies across treatments (see Appendix). After transfer, all individuals were maintained at $30^{\circ} \mathrm{C}$ up to the determination of the sexual morph, at a minimum size of about $3 \mathrm{~mm}$. In all treatments, juveniles hatched in the box in which they were laid. We arranged for the number of juveniles per box to be less than 10 in order to minimise density effects on growth (Dillon, 2000). The position of boxes in the rearing rooms was regularly randomised. Phally status was determined in 808 individuals, that is 451 for genotype 1 and 440 for genotype 2 (detailed results in the Appendix).

\section{Statistical analysis}

With respect to the experimental design, the onset $a$ and the offset $b$ of the effect of temperature on phallus development correspond respectively to the ages at transfer before and beyond which aphally ratios (ARs) remain constant. Let $p_{t}$ be the probability that an individual switched to $30^{\circ} \mathrm{C}$ at time (age) $t$ ends up into the aphallic state. As high temperatures favour aphally, the AR should decrease when the age at transfer increases from $a$ to $b$. Accordingly, the logit transformed probability of being aphallic at time $t$ can be described as:

$$
\left\{\begin{array}{cl}
L N\left(p_{t} / 1-p_{t}\right)=\alpha+\frac{(\beta-\alpha) t}{(b-a)} & \text { for } a<t<b \\
\operatorname{Ln}\left(p_{t} / 1-p_{t}\right)=\alpha & \text { for } t<a \\
\operatorname{Ln}\left(p_{t} / 1-p_{t}\right)=\beta & \text { for } t>b
\end{array}\right.
$$

This model is flexible enough to allow for various effects of the environmental variable, when changing values of $a, b, \alpha$ and $\beta$. For example, if $a=b$ and $\alpha \neq \beta$, the probability to end up into the aphallic state depends only on the temperature experienced at time $a$ exactly (switchpoint model below). When $a \neq b$, the above equation (1) describes a discontinuous line, as the AR changes gradually between ages $a$ and $b$ and remains constant outside of this interval. A continuous curve could also be fitted; however the discontinuous model has the advantage of providing precise estimations of $a$ and $b$. Moreover, a continuous curve would imply an action of the environment from time $-\infty$ to $+\infty$, which, however weak this effect might be, is not biologically meaningful. We here took advantage of the model's flexibility, both considering a series of nested models and testing for genotypespecific effects. In a first step, the goodness of fit of each model was estimated using a maximum likelihood procedure, either considering each genotype separately, or considering the whole dataset as a single homogeneous group. The performances of the different models were compared. We considered a complete model (12 parameters, that is that the AR was estimated separately for each treatment), a gradual model (four parameters: $a, b$, $\alpha$ and $\beta$ ), a switch-point model (three parameters: $a=b$, $\alpha$ and $\beta$ ) and a null model (one parameter, $\alpha=\beta$, that is constant AR). The log-likelihood of a model was given by :

$$
\operatorname{Ln}(L)=\sum_{t}\left(a_{t} \operatorname{Ln}\left(p_{t}\right)+e_{t} \operatorname{Ln}\left(1-p_{t}\right)\right)
$$

where $a_{t}$ and $e_{t}$ were the number of aphallic and euphallic individuals respectively that were transferred at age $t$, and $p_{t}$ is the corresponding probability of being aphallic under the model considered. For the gradual and switchpoint models, $p_{t}$ was calculated using equation (1), imposing $a=b$ in (1.2) and dropping the equation (1.1) for the switch-point model. A Mathematica (Wolfram, 1991) program was written to estimate numerically values of $a$, $b, \alpha$ and $\beta$ that maximise the likelihood under these models. For the complete model, the best fit was obtained for:

$$
\hat{p}_{t}=\frac{a_{t}}{a_{t}+e_{t}},
$$


Table 2 Results of the likelihood-ratio tests performed on different versions ( $c$ and $f$ holding for genotype constrained or free to vary) of the gradual, switch-point and null models

\begin{tabular}{|c|c|c|c|c|c|c|c|}
\hline Model & Version & $\operatorname{Ln}(L)$ & Dev. & $N_{i}$ & $X^{2}$ & $N_{i}-N_{j}$ & $P$ \\
\hline \multirow[t]{2}{*}{ complete } & $f$ & -503.889 & 0 & 24 & 44.464 & 12 & $<10^{-4}$ \\
\hline & $c$ & -526.121 & 44.464 & 12 & - & - & - \\
\hline \multirow[t]{2}{*}{ gradual } & $f$ & -510.503 & 13.228 & 8 & 42.25 & 4 & 0.0003 \\
\hline & $c$ & -531.626 & 55.474 & 4 & - & - & - \\
\hline \multirow[t]{2}{*}{ switch-point } & $f$ & -511.888 & 15.998 & 6 & 39.51 & 3 & 0.0002 \\
\hline & $c$ & -531.643 & 55.508 & 3 & - & - & - \\
\hline \multirow[t]{2}{*}{ null } & $f$ & -542.295 & 76.812 & 2 & 25.85 & 1 & 0.0003 \\
\hline & $c$ & -529.371 & 50.964 & 1 & - & - & - \\
\hline
\end{tabular}

$\operatorname{Ln}(\mathrm{L})$ is the log-likelihood and Dev. the total deviance (twice the difference in $\operatorname{Ln}(\mathrm{L})$ between the model considered and the complete model). $N_{i}$ refers to the number of independent parameters, $X^{2}$ to twice the difference in log-likelihood between two successive models ( $f$ vs $c$ for the gradual, switch-point and null models), $N_{i}-N_{j}$ to the difference in number of independent parameters between two successive models and $P$ to the corresponding probability of the $\chi^{2}$ test. $-=$ irrelevant.

whereas for the null model it was obtained for:

$$
\hat{p}_{t}=\frac{\sum_{t} a_{t}}{\sum_{t}\left(a_{t}+e_{t}\right)} .
$$

The maximum log-likelihood was obtained from equation (2). Models were compared by calculating the change in deviance $X^{2}=2\left(\operatorname{Ln}(L)_{\text {model } 1}-\operatorname{Ln}(\mathrm{L})_{\text {model } 2}\right)$. This follows a $\chi^{2}$ distribution with $N_{1}-N_{2}$ degrees of freedom $\left(N_{i}\right.$ being the number of independent parameters estimated in model $i$; see McCullagh and Nelder, 1983).

\section{Results}

The results are summarised in Tables 2 and 3 and in Figure 2. The ARs obtained for genotypes 1 and 2 ranged from 0.10 to 0.57 and 0.26 to 0.65 respectively. Although these extreme values were similar for the two genotypes, the distribution of the ARs among treatments differed between them (Figure 2); a significant reduction in deviance was obtained when the two genotypes were fitted separately under each model ( $f$ and $c$ versions in Table 2). For genotype 1 , the probability of being aphallic increased when the time spent at $25^{\circ} \mathrm{C}$ decreased, suggesting an influence of temperature (Figure 2a). In contrast, no such change was observed for genotype 2, suggesting no sensitivity to temperature (Figure $2 b$ ). This is supported by the likelihood-ratio tests performed on the different models for each genotype separately. For genotype 2, the best model was the null model $(\hat{P}=0.46$, $\mathrm{SE}=0.05)$. On the other hand, the switch-point model performed better than the null model for genotype 1 . Further, the gradual model was not superior in fit to the switch-point model (Table 3). Under the switch-point model, the best estimate for the age at onset and offset of the effect of temperature was $a=b=1.5$ days (95\% confidence intervals : 0.25 to 5.25 days), while the estimates were $a=0.25$ and $b=6.25$ days (95\% confidence intervals: -3 to 4.5 days and 2 to 13.5 days respectively) under the gradual model. The corresponding $\alpha$ and $\beta$ were 0.42 and $0.18\left(\mathrm{SE}_{\alpha}=0.07 ; \mathrm{SE}_{\beta}=0.05\right)$ under the switch-point model and 0.43 and $0.14\left(\mathrm{SE}_{\alpha}=0.08 ; \mathrm{SE}_{\beta}=\right.$ $0.06)$ under the gradual model.

\section{Discussion}

The results obtained for the Kobouri (g1) and the Namaga (g2) genotypes are consistent with a previous study (Ostrowski et al, 2000), in which no genetic variation was detected for the AR between several Kobouri genotypes, although they all were sensitive to temperature. The AR estimated over all Kobouri genotypes were 0.07 (SE = $0.04)$ and $0.54(\mathrm{SE}=0.09)$ at 25 and $30^{\circ} \mathrm{C}$ respectively, which are comparable with the $\alpha(0.18 ; \mathrm{SE}=0.05)$ and $\beta(0.42 ; \mathrm{SE}=0.07)$ values obtained here for the Kobouri

Table 3 Results of the likelihood-ratio tests performed on the complete, gradual, switch-point and null models for for genotypes $g_{1}$ and $\mathrm{g}_{2}$ separately

\begin{tabular}{|c|c|c|c|c|c|c|c|}
\hline Model & Genotype & $\operatorname{Ln}(L)$ & Dev. & $N_{i}$ & $X^{2}$ & $N_{i}-N_{j}$ & $P$ \\
\hline \multirow[t]{2}{*}{ complete } & $\mathrm{g}_{1}$ & -232.881 & 0 & 12 & 1.79 & 8 & 0.99 \\
\hline & $\begin{array}{l}\mathrm{O}_{2} \\
\mathrm{~g}_{2}\end{array}$ & -271.008 & 0 & 12 & 11.44 & 8 & 0.17 \\
\hline \multirow[t]{2}{*}{ gradual } & $\mathrm{g}_{1}$ & -233.775 & 1.79 & 4 & 2.71 & 1 & 0.099 \\
\hline & $\begin{array}{l}\mathrm{g}_{2} \\
\mathrm{~g}_{2}\end{array}$ & -276.728 & 11.44 & 4 & 0.50 & 1 & 0.48 \\
\hline \multirow[t]{2}{*}{ switch-point } & $\mathrm{g}_{1}$ & -235.129 & 4.496 & 3 & 33.15 & 2 & $<10^{-8}$ \\
\hline & $\begin{array}{l}\mathrm{g}_{2} \\
\mathrm{~g}_{2}\end{array}$ & -276.975 & 11.934 & 3 & 1.39 & 2 & 0.24 \\
\hline \multirow[t]{2}{*}{ null } & $\mathrm{g}_{1}$ & -251.702 & 37.642 & 1 & - & - & - \\
\hline & $\mathrm{g}_{2}$ & -277.669 & 13.32 & 1 & - & - & - \\
\hline
\end{tabular}

$\operatorname{Ln}(\mathrm{L})$ is the log-likelihood and Dev. the total deviance (twice the difference in $\operatorname{Ln}(\mathrm{L})$ between the model considered and the complete model). $N_{i}$ refers to the number of independent parameters, $X^{2}$ to twice the difference in log-likelihood between two successive models (complete vs gradual, gradual vs switch-point and switch-point vs null), $N_{i}-N_{j}$ to the difference in number of independent parameters between two successive models and $P$ to the corresponding probability of the $\chi^{2}$ test. $-=$ irrelevant. 
a

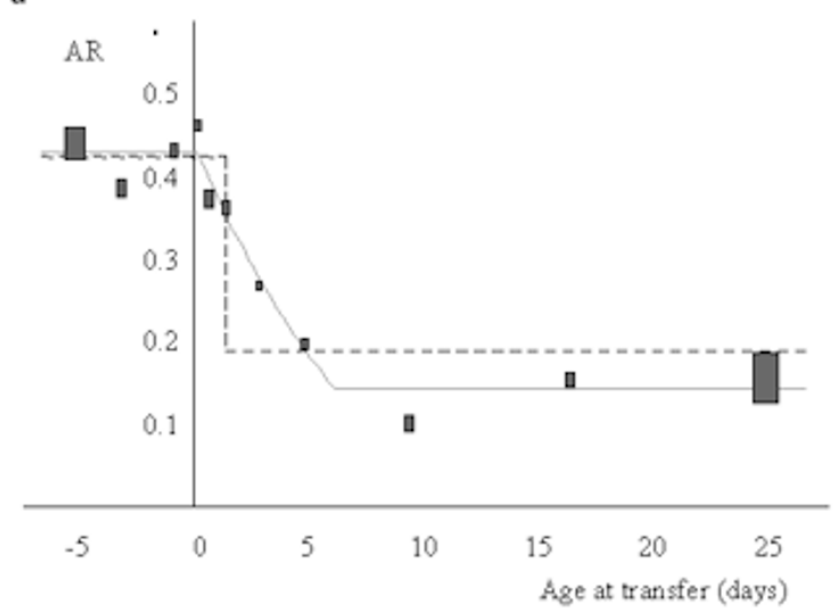

b

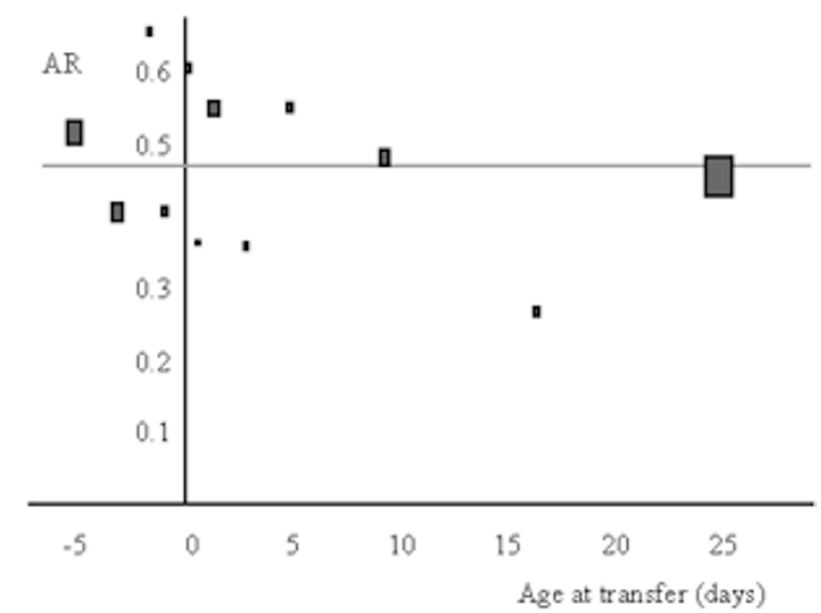

Figure 2 Aphally ratio (AR) as a function of age of $\mathrm{G}_{n+2}$ individuals at transfer (see Table 1). Each rectangle refers to a treatment (from 12 to 1 with increasing values on the $x$-axis), and its area is proportional to the total number of individuals checked for their phally status (see Appendix). (a) Genotype 1. The best-fit curves under the switch-point and the gradual model are respectively depicted as a dotted and a full line. Under the switch-point model, the best estimate for the age at onset and offset of the effect of temperature was $a=b=1.5$. Under the gradual model, the values were $a=0.25$ and $b=6.25$. (b) Genotype 2. The best fit line under the null model is depicted as a full line $(\hat{P}=0.46 ; \mathrm{SE}=0.05)$.

genotype under the switch-point model and similar environmental conditions. In contrast, some genetic variation was detected for both AR and sensitivity to temperature $(\mathrm{G} \times \mathrm{E}$ interaction) between Namaga genotypes (Ostrowski et al, 2000), and not all were found to be sensitive to temperature. As the ontogenetic reaction norm was best fitted by the switch-point model for $\mathrm{g} 1$ and by the null model for g2, the results of the switch experiment reflect, to a limited extent, the genetic variability for the sensitivity of aphally to temperature.

The dispersion around the fitted lines (Figure 2) markedly differed between the two genotypes. This may be explained in several ways. First, as increasing deviance may result from decreased numbers of free parameters, part of this discrepancy is due to the difference in number of parameters between the models fitted (four for the gradual, three for the switch-point, and one for the null model). Second, as the binomial error depends on $p$ and reaches a maximum value for $P=0.5$, part of the greater dispersion in genotype 2 could be attributed to a greater binomial sampling error, since the single estimated parameter in genotype 2 is $\hat{P}=0.46$. Third, maternal effects on AR cannot be excluded, but would have to be of different magnitude to explain the difference in dispersion between the two genotypes. However, a previous study indicated that mothers from a given genotype produce similar ARs in the same controlled conditions (Ostrowski et al, 2000).

As a consequence of the genetic variability for sensitivity to temperature, the estimation of the ontogenetic parameters of aphally is relevant for the Kobouri genotype only. Our results indicate that the gradual model does not provide a significantly better description of data than the switch-point model, although we note that the associated probability is rather low (Table 3; $P=0.099$ ) and the fit visually satisfactory (Figure 2a). It remains possible that this result is due to insufficient sampling effort between the onset and offset of temperature effect, in addition to the large sampling error inherent to binary traits, and it calls for larger-scale experiments.

The estimated values of the age at onset under both models (1.5 and 0.25 days under the switch-point and gradual model respectively) suggest that the temperature prior to oviposition has no effect on phallus development (Figure 2a). These values also imply that the developmental temperature has an effect as soon as eggs are laid. At the temperatures used here, the hatching time is about 5-8 days (Doums et al, 1998a). The estimated value of the age at offset under both models (1.5 and 6.25 days) therefore strongly suggest that temperature has no effect beyond hatching. These results imply that individuals cannot, or only to a very limited extent, choose the environment in which their own sexual morph is determined. In contrast with the macropterous species G. firmus (Roff and Shannon, 1993), it seems unlikely that B. truncatus individuals have the possibility to modify the expression of their genetic propensity through their own behaviour (eg actively moving towards environments with specific temperatures), changing the potential response of aphally to selection. However, the set of conditions used in this experiment was restricted to one pair of initial/arrival temperatures $\left(25 \rightarrow 30^{\circ} \mathrm{C}\right)$. Other sets could reveal a more complex situation as, for instance, change in temperature may not be symmetrical in effect. A reverse switch experiment would therefore yield more complete results, especially to assess the effect of temperature 'within the mother', that is before the eggs are laid. Further, it remains possible that mothers are able to choose laying sites with specific temperatures which would lead to the same consequences than offspring choice on apparent genetic variation. Although egglaying preferences of $B$. truncatus are poorly known in nature, adults of this species showed no particular preference under laboratory conditions for any particular area of a thermal gradient ranging from 12 to $38^{\circ} \mathrm{C}$ (Chernin, 1967).

The adaptive nature of environmental phally determination (EPD) remains however ambiguous. This situation parallels that of environmental sex determination (ESD), for which adaptive hypotheses received ambiguous support from empirical data (Bull and Charnov, 1989; Rhen 
and Lang, 1998). In the ESD framework (see Charnov, 1982, pp 37-66), the adaptiveness of environmental determination relies on a differential gain in fitness between morphs when environment changes. Similarly, the adaptive nature of EPD could rely on a differential gain in fitness between the sexual morphs when temperature changes. This remains to be precisely investigated in Bulinus. Bull (1981) emphasised that adaptive ESD evolution is possible only if individuals cannot choose the environment in which they develop; otherwise they will choose the environment that confers the highest fitness, buffering the required heterogeneity for adaptive evolution. For the EPD to be adaptive, this criteria can be interpreted as imposing the sexual morph to be entirely determined before hatching, that is before juveniles are mobile, which is consistent with our results.

Although the range of environmental conditions and genotypes used in this study was limited, the methodology and models employed may be used to evaluate genetic variation of ontogenetic parameters, as well as to address other biological questions about environmental determination. This may be applied to any other plastic trait with binomial error, using an appropriate statistical framework. Exploring the genetic variability of this kind of traits can be informative at many levels. Changing the timing of gene action (heterochrony) is considered to be a fundamental way of altering adult phenotypes in relatively short periods of time (McKinney and McNamara, 1991). Genetic variability in the length of the ontogenetic time window and in the rate of development of binary traits could well be a mechanism by which sensitivity is altered and eventually targeted by natural selection.

\section{Acknowledgements}

The authors are grateful to A Tsitrone and T Lenormand for critical reading of the manuscript. This work was supported by funds from the Centre National de la Recherche Scientifique (CNRS) to UPR 9056 (Centre d'Ecologie Fonctionnelle et Evolutive). This work is part of the PhD project of Marie-France Ostrowski which is supported by funds from the NSERC (Natural Sciences and Engineering Research Council of Canada) and the FRM (Fondation pour la Recherche Médicale).

\section{References}

Bull JJ (1981). Evolution of environmental sex determination from genotypic sex determination. Heredity 47: 173-184.

Bull JJ, Charnov EL (1989). Enigmatic reptilian sex ratios. Evolution 43: 1561-1566.

Bull JJ, Vogt RC, Bulmer MG (1982). Heritability of sex ratio in turtles with environmental sex determination. Evolution 36 : 333-341.

Charnov EL (1982). The Theory of Sex Allocation. Princeton University Press: Princeton.

Chernin E (1967). Behavior of Biomphalaria glabrata and other snails in a thermal gradient. J Parasitol 53: 1233-1240.
Dillon RTJ (2000). The Ecology of Freshwater Molluscs. Cambridge University Press: Cambridge.

Doums C, Brémond P, Delay B, Jarne P (1996). The genetical and environmental determination of phally polymorphism in the freshwater snail Bulinus truncatus. Genetics 142: 217-225.

Doums C, Perdieu M-A, Jarne P (1998a). Resource allocation and stressful conditions in the aphallic snail Bulinus truncatus. Ecology 79: 720-733.

Doums C, Viard F, Jarne P (1998b). The evolution of phally polymorphism. Biol J Linn Soc 64: 273-296.

Gould SJ (1977). Ontogeny and Phylogeny. Harvard University Press: Cambridge.

Janzen FJ, Paukstis GL (1991). Environmental sex determination in reptiles: ecology, evolution, and experimental design. Quart Rev Biol 66: 149-179.

Jarne P, Finot L, Bellec C, Delay B (1992). Aphally versus euphally in self-fertile hermaphrodite snails from the species $\mathrm{Bul}$ inus truncatus (Pulmonata : Planorbidae). Am Nat 139: 424432.

Larambergue MD (1939). Etude de l'autofécondation chez les gastéropodes pulmonés: recherches sur l'aphallie et la fécondation chez Bulinus (Isidora) contortus. Bull Biolog France et Belgique 73: 19-231.

Lynch M, Walsh B (1998). Genetics and Analysis of Quantitative Traits. Sinauer: Sunderland, MA.

McCullagh HP, Nelder JA (1983). Generalized Linear Models. Cambridge University Press: Cambridge.

McKinney ML, McNamara KJ (1991). Heterochrony. The evolution of ontogeny. Plenum: New York, New York.

Ostrowski M-F, Jarne P, David P (2000). Quantitative genetics of sexual plasticity: the Environmental Threshold Model and genotype-by-environment interaction for phallus development in the snail Bulinus truncatus. Evolution 54: 1614-1625.

Paoletti C, Holsinger KE (1999). Spatial patterns of polygenic variation in Impatiens capensis, a species with an environmental controlled mixed mating system. I Evol Biol 12: 689-696.

Pigliucci M, Schlichting CW (1995). Ontogenetic reaction norms in Lobelia siphilitica (lobeliaceae): response to shading. Ecology 76: 2134-2144.

Rhen T, Lang JW (1998). Among-family variation for environmental sex determination in reptiles. Evolution 52: 1514-1520.

Roff DA (1997). Evolutionary Quantitative Genetics. Chapman \& Hall: London.

Roff DA, Bradford MJ (1999). A quantitative genetic analysis of phenotypic plasticity of diapause in the cricket Allonemobius socius. Heredity 84: 193-200.

Roff DA, Shannon P (1993). Genetic and ontogenetic variation in behavior: its possible role in the maintenance of genetic variation in the wing dimorphism of Gryllus Firmus. Heredity 71: 481-487.

Schrag SJ, Ndifon GT, Read AF (1994). Temperature-determined outcrossing ability in wild populations of a simultaneous hermaphrodite snail. Ecology 75: 2066-2077.

Schrag SJ, Read AF (1992). Temperature determination of male outcrossing ability in a simultaneous hermaphrodite. Evolution 46: 1698-1707.

Viard F, Doums C, Jarne P (1997). Selfing, sexual polymorphism and microsatellites in the hermaphroditic freshwater snail Bulinus truncatus. Proc R Soc B 264: 39-44.

Waller DM (1980). Environmental determinants of outcrossing in Impatiens capensis (Balsaminaceae). Evolution 34: 747-761.

Wolfram S (1991). Mathematica: a system for doing mathematics by computer. Addison-Wesley Publishing Company. 
Appendix

Aphally ratio obtained for the two genotypes studied for the twelve treatments

\begin{tabular}{|c|c|c|c|c|c|c|}
\hline \multirow[t]{2}{*}{ Treatment } & \multicolumn{3}{|c|}{ Genotype 1} & \multicolumn{3}{|c|}{ Genotype 2} \\
\hline & $N_{A}$ & $N$ & $N_{A} / N$ & $N_{A}$ & $N$ & $N_{A} / N$ \\
\hline 1 & 14 & 92 & 0.15 & 40 & 89 & 0.45 \\
\hline 2 & 4 & 27 & 0.15 & 6 & 23 & 0.26 \\
\hline 3 & 3 & 31 & 0.10 & 19 & 40 & 0.48 \\
\hline 4 & 5 & 26 & 0.19 & 12 & 22 & 0.55 \\
\hline 5 & 5 & 19 & 0.26 & 6 & 17 & 0.35 \\
\hline 6 & 10 & 28 & 0.36 & 18 & 33 & 0.55 \\
\hline 7 & 14 & 38 & 0.37 & 5 & 14 & 0.36 \\
\hline 8 & 11 & 24 & 0.46 & 15 & 25 & 0.60 \\
\hline 9 & 12 & 28 & 0.43 & 10 & 25 & 0.40 \\
\hline 10 & 4 & 7 & 0.57 & 13 & 20 & 0.65 \\
\hline 11 & 13 & 34 & 0.38 & 18 & 45 & 0.40 \\
\hline 12 & 27 & 62 & 0.44 & 25 & 49 & 0.51 \\
\hline
\end{tabular}

$\mathrm{N}_{\mathrm{A}}$ and $\mathrm{N}$ are the number of aphallic snails and the total number of snails analysed. $\mathrm{N}_{\mathrm{A}} / \mathrm{N}$ is the aphally ratio. 